University of Nebraska - Lincoln

DigitalCommons@University of Nebraska - Lincoln

$10-1-2001$

\title{
Energetics and cooperativity in three-center hydrogen bonding interactions. II. Intramolecular hydrogen bonding systems
}

\author{
Ruben D. Parra \\ University of Nebraska-Lincoln, rparra1@depaul.edu \\ Bing Gong \\ State University of New York at Buffalo \\ Xiao Cheng Zeng \\ University of Nebraska-Lincoln, xzeng1@unl.edu
}

Follow this and additional works at: https://digitalcommons.unl.edu/chemzeng

Part of the Chemistry Commons

Parra, Ruben D.; Gong, Bing; and Zeng, Xiao Cheng, "Energetics and cooperativity in three-center hydrogen bonding interactions. II. Intramolecular hydrogen bonding systems" (2001). Xiao Cheng Zeng Publications. 43.

https://digitalcommons.unl.edu/chemzeng/43

This Article is brought to you for free and open access by the Published Research - Department of Chemistry at DigitalCommons@University of Nebraska - Lincoln. It has been accepted for inclusion in Xiao Cheng Zeng Publications by an authorized administrator of DigitalCommons@University of Nebraska - Lincoln. 


\title{
Energetics and cooperativity in three-center hydrogen bonding interactions. II. Intramolecular hydrogen bonding systems
}

\author{
Rubén D. Parra ${ }^{\mathrm{a})}$ \\ Department of Chemistry, University of Nebraska-Lincoln, Lincoln, Nebraska 68588 \\ Bing Gong \\ Department of Chemistry, Natural Sciences Complex, State University of New York, Buffalo, \\ New York 14260 \\ X. C. Zeng \\ Department of Chemistry, University of Nebraska-Lincoln, Lincoln, Nebraska 68588
}

(Received 6 April 2001; accepted 16 July 2001)

\begin{abstract}
High level ab initio calculations have been carried out on a number of intramolecular two- and three-center H-bonding structures containing the amide motif, $\mathrm{NHC}=\mathrm{O}$. These structures serve as model systems for probing the stability of intramolecular three-center $\mathrm{H}$ bonds of the type $\mathrm{A}_{1} \mathrm{HA}_{2}$. Particular attention is given to cooperative effects in the three-center $\mathrm{H}$-bonding structures. A systematic assessment of cooperativity for intramolecular H-bonding systems is presented. (C) 2001 American Institute of Physics. [DOI: 10.1063/1.1400142]
\end{abstract}

\section{INTRODUCTION}

In paper I of this work, we studied intermolecular threecenter $\mathrm{H}$-bonding interactions in diacetamide- $\mathrm{X}$ dimers $\left(\mathrm{X}=\mathrm{HCN}, \mathrm{CH}_{3} \mathrm{OH}\right)$. Our previous results show that, in the model systems considered, the formation of an intermolecular three-center $\mathrm{H}$ bond is a process that gives rise to negative cooperative effects as clearly demonstrated by the energetics, geometry, vibrational frequencies, and proton chemical shifts. ${ }^{1}$ However, the issue of cooperativity in intramolecular three-center $\mathrm{H}$ bonding is still open to research. In this paper, we turn our attention to a number of systems containing intramolecular three-center $\mathrm{H}$ bonding of the type $\mathrm{A}_{1} \mathrm{HA}_{2}$. We investigate the effects of having the proton donor as well as the proton acceptor atoms rigidly held within the same molecule.

In this study, we mainly focus on the intramolecular $\mathrm{H}$-bond interactions in a series of $R-\mathrm{CONH}-R^{\prime}$ molecules. The model structures are depicted in Fig. 1, where threecenter H-bonded structures (1-4) are chosen to investigate cooperativity. Because the definition and evaluation of intramolecular $\mathrm{H}$-bond interaction energies is by far not obvious, ${ }^{2}$ we have chosen to investigate the effects of cooperativity using properties other than energetics. The ability to define and describe cooperativity with parameters other than energetics is particularly important for intramolecular $H$-bonded systems. Several groups have shown that a quantitative treatment of cooperativity effects in intermolecular and intramolecular $\mathrm{H}$ bonds can be achieved in terms of the relative vibrational frequency shifts undergone by the $\mathrm{A}-\mathrm{H}$ group involved in hydrogen bonding. ${ }^{3}$ Cooperative phenomena have been successfully studied by means of geometries, dipole moments, vibrational spectra, vibrational mode inten-

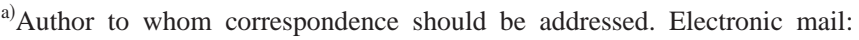
rparra1@wppost.depaul.edu
}

sities, and quadrupole coupling constants. ${ }^{4}$ The cooperative effects manifested in these properties have been shown to parallel those seen in the energetics.

The parameters chosen to investigate cooperative effects should be sensitive to $\mathrm{H}$ bonding, and less (or not) sensitive to other interactions. In this study, the cooperative effects are described in terms of the $\mathrm{N}-\mathrm{H}$ bond lengths, the $\mathrm{N}-\mathrm{H}$ stretching and bending frequencies, and the $\mathrm{N}-\mathrm{H}{ }^{1} \mathrm{H}-\mathrm{NMR}$ chemical shifts. In paper I of this work we showed that the cooperativity effects manifested in these parameters correlate closely with those seen in the energetics. Thus these parameters should provide reliable information as far as cooperativity is concerned. A series of isodesmic reactions are also devised to gain insight into the enthalpy change associated with the formation of a three-center $\mathrm{H}$-bonded structure from a pair of two-center H-bonded structures.

\section{COMPUTATIONAL DETAILS}

All the computations were carried out using the GAUSSIAN 98 program. ${ }^{5}$ The geometries of the different systems were optimized at B3LYP/6-311++G(d,p) level. The same level of theory was used to compute harmonic vibrational frequencies that in turn were used to verify that each structure corresponded to a minimum on the potential energy surface. Vibrational frequencies were used to obtain the zeropoint energy (ZPE) correction to the electronic energy. Geometry optimizations were also conducted at the MP2/6-31G(d) level to ensure that the results are robust, given the improvement in the correlation method. The optimized geometries were used to compute single point energies at the MP2/6-311++G(2d,2p) level, and ${ }^{1} \mathrm{H}-\mathrm{NMR}$ chemical shielding constants at the $\mathrm{B} 3 \mathrm{LYP} / 6-311+\mathrm{G}(2 \mathrm{~d}, \mathrm{p})$ level. In this study cooperative effects are highlighted using several indicators such as the frequency shifts undergone by the $\mathrm{N}-\mathrm{H}$ stretching and out-of-plane bending modes, the in- 
<smiles>C=CNC(=O)C=C</smiles><smiles>C=CC(=O)N1CCOC1COC</smiles>

46<smiles>C=CN1C(=O)C=CC2COCC21</smiles><smiles>O=C1C=CC(=O)COC1</smiles>

3a<smiles>COc1ccccc1N1C(=O)C2CCCC(O2)C1CO</smiles>

3

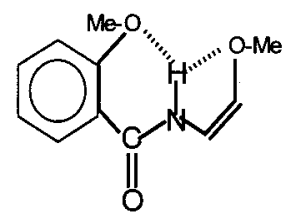

2
FIG. 1. Reference structures and $\mathrm{H}$-bonding structures considered in this work.<smiles>C=CNC(=O)c1ccccc1</smiles>

$2 c$
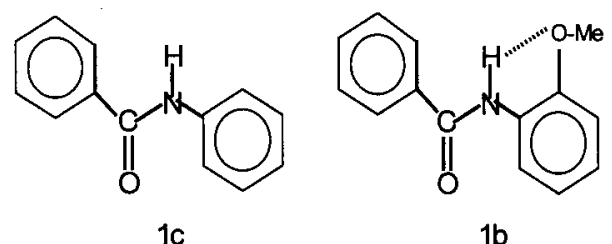

$1 b$

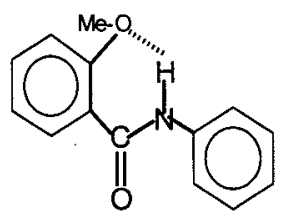

$1 a$

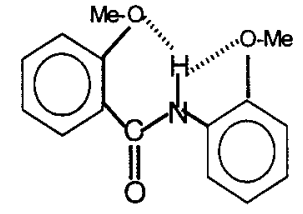

1 crease in the intensity of the $\mathrm{N}-\mathrm{H}$ stretching mode, the lengthening of the donor $\mathrm{N}-\mathrm{H}$ bond, and ${ }^{1} \mathrm{H}-\mathrm{NMR}$ chemical shifts.

\section{RESULTS AND DISCUSSIONS}

Geometries. The formation of an intramolecular $\mathrm{H}$ bond is accompanied by structural changes that help the proton donor and the proton acceptor units to attain a proper arrangement for the interaction. Relevant structural parameters are depicted in Fig. 3(a) of Paper I. An H bond in a sixmembered ring is described in terms of $r, d_{1}, R_{1}$, and $\phi_{1}$. An $\mathrm{H}$ bond in a five-membered ring is described in terms of $r, d_{2}, R_{2}$, and $\phi_{2}$. The $\mathrm{N}-\mathrm{H}$ distance, $r$, will be discussed in the context of cooperative effects. A three-center $\mathrm{H}$ bond is characterized by the combination of the structural parameters used to describe the independent two-center $\mathrm{H}$ bonds. Table I lists the relevant geometric information.

Both B3LYP and MP2 optimized geometries show that an $\mathrm{H}$ bond in a six-membered ring has a more favorable geometry arrangement than that in a five-membered ring. This is reflected in shorter $\mathrm{O} \cdots \mathrm{H}$ distances $\left(d_{1}<d_{2}\right)$ and larger $\mathrm{N}-\mathrm{H} \cdots \mathrm{O}$ angles $\left(\phi_{1}>\phi_{2}\right)$. Table I shows that a phenyl group strengthens the $\mathrm{H}$ bonds, as seen by shortening of the $\mathrm{O} \cdots \mathrm{H}$ distances and widening of the $\mathrm{N}-\mathrm{H} \cdots \mathrm{O}$ angles.
The $\mathrm{O} \cdots \mathrm{N}$ distances, $R_{1}$ and $R_{2}$, are shortened only when the phenyl group is directly involved in the $\mathrm{H}$ bonds.

The calculated dihedral $\mathrm{HNC}=\mathrm{O}$ angles are around 173.4 degrees and 180.0 degrees in the five- and sixmembered ring systems, respectively. The larger $s p^{2}$ hybridization at the nitrogen atom leads to a more acidic character of the amide motif, which in turn enhances the H-bond interaction in the six-membered ring structures.

Vibrational and ${ }^{1} \mathrm{H}-\mathrm{NMR}$ results. It is well known that certain normal modes of vibration are significantly disturbed by $\mathrm{H}$-bond formation. The changes are so distinctive that vibrational studies indeed provide the most commonly used criteria for the presence of an $\mathrm{H}$ bond. ${ }^{6}$ Some major spectral changes, relative to the reference systems, that are expected to occur when an $\mathrm{H}$ bond forms are (1) the $\mathrm{N}-\mathrm{H}$ bending frequency increases, (2) the $\mathrm{N}-\mathrm{H}$ stretching frequency decreases, and (3) the intensity of the $\mathrm{N}-\mathrm{H}$ stretching frequency increases. The intensity behavior is determined by the charge distribution in the $\mathrm{H}$ bond and its movement during vibration, and is therefore as characteristic of $\mathrm{H}$-bond formation as is the $\nu_{\mathrm{N}-\mathrm{H}}$ frequency shift. ${ }^{7}$

Table II displays the $\mathrm{N}-\mathrm{H}$ bond lengths and ${ }^{1} \mathrm{H}-\mathrm{NMR}$ chemical shifts of the B3LYP geometries. It is worth mentioning that the corresponding values for the MP2 optimized 
TABLE I. Relevant H-bond structural parameters. ${ }^{\text {a }}$

\begin{tabular}{|c|c|c|c|c|c|c|c|}
\hline \multicolumn{8}{|c|}{ B3LYP/6-311++G(d,p) optimized geometries } \\
\hline & $d_{1}$ & $R_{1}$ & $\phi_{1}$ & & $d_{2}$ & $R_{2}$ & $\phi_{2}$ \\
\hline $4 a$ & 2.024 & 2.812 & 132.9 & $4 b$ & 2.437 & 2.783 & 99.3 \\
\hline $3 a$ & 1.995 & 2.818 & 136.7 & $3 b$ & 2.115 & 2.611 & 108.0 \\
\hline $2 a$ & 1.884 & 2.694 & 134.7 & $2 b$ & 2.431 & 2.782 & 99.6 \\
\hline \multirow[t]{2}{*}{$1 a$} & 1.853 & 2.696 & 138.6 & $1 b$ & 2.109 & 2.609 & 108.4 \\
\hline & $d_{1}$ & $R_{1}$ & $\phi_{1}$ & & $d_{2}$ & $R_{2}$ & $\phi_{2}$ \\
\hline 4 & 2.033 & 2.806 & 131.4 & & 2.493 & 2.808 & 97.4 \\
\hline 3 & 2.018 & 2.820 & 134.3 & & 2.147 & 2.622 & 106.6 \\
\hline 2 & 1.888 & 2.685 & 133.3 & & 2.498 & 2.807 & 97.0 \\
\hline 1 & 1.869 & 2.693 & 136.1 & & 2.155 & 2.623 & 106.1 \\
\hline \multicolumn{8}{|c|}{ MP2/6-31G(d) optimized geometries } \\
\hline & $d_{1}$ & $R_{1}$ & $\phi_{1}$ & & $d_{2}$ & $R_{2}$ & $\phi_{2}$ \\
\hline $4 a$ & 1.986 & 2.784 & 133.5 & $4 b$ & 2.380 & 2.749 & 100.4 \\
\hline $3 a$ & 1.947 & 2.783 & 137.6 & $3 b$ & 2.089 & 2.587 & 107.9 \\
\hline $2 a$ & 1.895 & 2.685 & 132.4 & $2 b$ & 2.370 & 2.746 & 100.7 \\
\hline \multirow[t]{2}{*}{$1 a$} & 1.830 & 2.679 & 138.9 & $1 b$ & 2.082 & 2.583 & 108.1 \\
\hline & $d_{1}$ & $R_{1}$ & $\phi_{1}$ & & $d_{2}$ & $R_{2}$ & $\phi_{2}$ \\
\hline 4 & 1.986 & 2.767 & 131.7 & & 2.416 & 2.763 & 99.0 \\
\hline 3 & 1.951 & 2.770 & 135.5 & & 2.104 & 2.589 & 106.9 \\
\hline 2 & 1.882 & 2.665 & 131.5 & & 2.405 & 2.755 & 99.1 \\
\hline 1 & 1.829 & 2.661 & 136.5 & & 2.100 & 2.586 & 106.9 \\
\hline
\end{tabular}

${ }^{a}$ Bond lengths, $d$ and $R$, in $\AA$; bond angles, $\phi$, in degrees.

structures are within $4 \%$ of those calculated with the B3LYP method and therefore are not reported. Also shown in Table II are the B3LYP/6-311++G(d,p) vibrational frequencies. Table III shows the changes relative to the reference systems in a way that helps the discussion of cooperative phenomena. Intensification factors $(A),{ }^{4,7}$ defined as the intensity of the $\nu_{\mathrm{N}-\mathrm{H}}$ mode in a given $\mathrm{H}$-bonded system divided by that in the corresponding reference structure, are also shown in Table III.

Table III shows that formation of a two-center $\mathrm{H}$ bond in a five-membered ring produces a small change in the $\mathrm{N}-\mathrm{H}$ stretching frequencies $\left(\nu_{\mathrm{N}-\mathrm{H}}\right)$, and a sizeable blueshift of the out-of-plane bending mode $\left(b_{\mathrm{N}-\mathrm{H}}\right)$. The predicted frequency shifts for $2 b$ and $4 b$ are close to each other, indicating similar strength of the H-bond interaction in both structures; the same is true for $1 b$ and $3 b$. The $\nu_{\mathrm{N}-\mathrm{H}}$ mode is slightly blue- shifted in $2 b$ and $4 b$, and slightly redshifted in $1 b$ and $3 b$. The predicted shifts to the blue of the $b_{\mathrm{N}-\mathrm{H}}$ mode in $1 b$ and $3 b$ are more than twice of those in $2 b$ and $4 b$. The $\mathrm{N}-\mathrm{H}$ bond elongations as well as the ${ }^{1} \mathrm{H}-\mathrm{NMR}$ chemical shifts found in $1 b$ and $3 b$ are larger than the corresponding changes found in $2 b$ and $4 b$. The results clearly show that the weak H-bond interaction involved in the five-membered ring systems is greatly enhanced by the presence of a phenyl group in the ring.

Table III shows that an $\mathrm{H}$ bond in a six-membered ring produces a sizeable redshift in the $\nu_{\mathrm{N}-\mathrm{H}}$ mode, a large blueshift in the $b_{\mathrm{N}-\mathrm{H}}$ mode, and a considerable shift to lower field of the ${ }^{1} \mathrm{H}-\mathrm{NMR}$ chemical shielding constants. As in the fivemembered ring systems, the presence of a phenyl group enhances the strength of the $\mathrm{H}$ bond in the six-membered ring systems. As expected, the superior strength of the H-bond

TABLE II. Calculated parameters for the $\mathrm{N}-\mathrm{H}$ bonds.

\begin{tabular}{lllllllll}
\hline \hline & $4 b$ & $3 b$ & $2 b$ & $1 b$ & $4 a$ & $3 a$ & $2 a$ & $1 a$ \\
\hline$\nu_{\mathrm{N}-\mathrm{H}}{ }^{\mathrm{a}}$ & 3626 & 3612 & 3631 & 3616 & 3584 & 3576 & 3571 & 3572 \\
$b_{\mathrm{N}-\mathrm{H}}$ & 586 & 639 & 583 & 637 & 633 & 640 & 661 & 648 \\
$r_{\mathrm{N}-\mathrm{H}}$ & 1.009 & 1.010 & 1.010 & 1.009 & 1.011 & 1.011 & 1.011 & 1.012 \\
$\delta_{\mathrm{N}-\mathrm{H}}{ }^{c}$ & 7.30 & 8.29 & 7.62 & 8.55 & 8.32 & 8.63 & 9.54 & 9.92 \\
& 4 & 3 & 2 & 1 & $4 c$ & $3 c$ & $2 c$ & $1 c$ \\
\hline$\nu_{\mathrm{N}-\mathrm{H}}{ }^{\mathrm{a}}$ & 3586 & 3561 & 3575 & 3541 & 3622 & 3620 & 3625 & 3623 \\
$b_{\mathrm{N}-\mathrm{H}}$ & 663 & 701 & 688 & 751 & 556 & 564 & 554 & 563 \\
$r_{\mathrm{N}-\mathrm{H}}{ }^{c}$ & 1.011 & 1.013 & 1.012 & 1.013 & 1.009 & 1.009 & 1.009 & 1.008 \\
$\delta_{\mathrm{N}-\mathrm{H}}$ & 8.43 & 9.21 & 9.61 & 10.43 & 6.99 & 7.13 & 7.33 & 7.48 \\
\hline \hline
\end{tabular}

${ }^{a}$ Frequencies in $\mathrm{cm}^{-1}$.

${ }^{b}$ Bond lengths in $\AA$.

${ }^{\mathrm{c}}$ Values relative to the calculated chemical shift of TMS (=31.91 ppm). 
TABLE III. Parameters for the $\mathrm{N}-\mathrm{H}$ bonds, relative to the corresponding reference structures.

\begin{tabular}{lllllll}
\hline \hline & $4 b$ & $4 a$ & 4 & $3 b$ & $3 a$ & 3 \\
\hline$\nu_{\mathrm{N}-\mathrm{H}}{ }^{\mathrm{a}}$ & 4 & -38 & -36 & -8 & -44 & -59 \\
$b_{\mathrm{N}-\mathrm{H}}$ & 30 & 77 & 107 & 75 & 76 & 137 \\
$A$ & 1.6 & 4.3 & 4.4 & 2.6 & 5.2 & 5.7 \\
$r_{\mathrm{N}-\mathrm{H}}{ }^{\mathrm{b}}$ & 0.000 & 0.002 & 0.002 & 0.001 & 0.002 & 0.004 \\
$\delta_{\mathrm{N}-\mathrm{H}}{ }^{\mathrm{a}}$ & 0.31 & 1.33 & 1.44 & 1.16 & 1.50 & 2.08 \\
& $2 b$ & $2 a$ & 2 & $1 b$ & $1 a$ & 1 \\
\hline$\nu_{\mathrm{N}-\mathrm{H}}{ }^{\mathrm{a}}$ & 6 & -54 & -50 & -7 & -51 & -82 \\
$b_{\mathrm{N}-\mathrm{H}}$ & 29 & 107 & 134 & 74 & 85 & 188 \\
$A$ & 1.6 & 8.4 & 8.1 & 2.5 & 8.9 & 9.8 \\
$r_{\mathrm{N}-\mathrm{H}}{ }^{\mathrm{b}}$ & 0.000 & 0.002 & 0.003 & 0.001 & 0.004 & 0.005 \\
$\delta_{\mathrm{N}-\mathrm{H}}$ & 0.29 & 2.21 & 2.28 & 1.07 & 2.44 & 2.95 \\
\hline \hline
\end{tabular}

${ }^{\mathrm{a}}$ Frequencies in $\mathrm{cm}^{-1}$.

${ }^{\mathrm{b}}$ Bond lengths in $\AA$.

${ }^{\mathrm{c}}$ Chemical shifts in ppm.

interaction in a six-membered ring over that in a fivemembered ring is manifested in the larger $\mathrm{N}-\mathrm{H}$ bond elongations, frequency shifts, and proton chemical shifts observed in the former. The relative strength of the two-center $\mathrm{H}$-bond systems follows the order $4 b, 2 b<3 b, 1 b<4 a$, $3 a<2 a, 1 a$.

Three-center H-bonds and cooperative effects. Table III shows that among the three-center H-bond structures (1-4) the largest frequency and chemical shifts occur in structure 1. This indicates that structure 1 presents the strongest threecenter H-bond interaction followed by structure 3. Structure 4 has the weakest three-center $\mathrm{H}$ bond.

Structures containing three-center $\mathrm{H}$-bond interactions are particularly suitable to investigate cooperative phenomena in multicenter $\mathrm{H}$-bond interactions. To investigate whether the components of a three-center interaction reinforce each other, that is, whether positive cooperative effects are taking place in the three-center systems studied, we pay particular attention to structural and spectral changes. Here, the cooperative effects are described in terms of the $\mathrm{N}-\mathrm{H}$ bond lengths, the $\mathrm{N}-\mathrm{H}$ stretching and bending frequencies, the intensity factor, and the ${ }^{1} \mathrm{H}-\mathrm{NMR}$ chemical shifts.

Table III shows that the $\mathrm{N}-\mathrm{H}$ bond lengths in 1-3 are increased, relative to the reference geometries, more than in $1 a-3 a$, and $1 b-3 b$, respectively. The effect is more pronounced in 1 . This enhanced lengthening of the $\mathrm{N}-\mathrm{H}$ bond is commonly used as one index to quantify cooperative effects. ${ }^{4,8}$ The $\mathrm{N}-\mathrm{H}$ bond in 4 presents no further elongation with respect to $4 a$.

Compared to the corresponding two-center H-bond structures, the $\mathrm{N}-\mathrm{H}$ bending mode is further blueshifted in 1-4. The $\mathrm{N}-\mathrm{H}$ stretching mode is further redshifted upon formation of the three-center structures 1 and 3 . Relative to $2 a$ and $4 a$, this mode is slightly blueshifted in 2 and 4 .

Formation of a three-center $\mathrm{H}$ bond in 1 and 3 increases the intensification factor relative to $1 a$ and $3 a$, respectively. Structure 4 shows a negligible increase in the intensification factor, and structure 2 shows a decrease.

In addition to vibrational studies, ${ }^{1} \mathrm{H}$ NMR chemical shifts can also be used to reveal cooperative phenomena. ${ }^{9}$ As
TABLE IV. Important relative energy data $(\mathrm{kcal} / \mathrm{mol}){ }^{\mathrm{a}}$

\begin{tabular}{lrrrr}
\hline \hline & $4 a-4 b$ & $3 a-3 b$ & $2 a-2 b$ & $1 a-1 b$ \\
\hline HF & -3.84 & -3.01 & 0.19 & 1.10 \\
MP2 & -4.72 & -1.11 & -2.95 & 0.59 \\
ZPE & 0.23 & 0.33 & -0.09 & 0.00 \\
$H_{0}$ & -4.49 & -0.78 & -3.04 & 0.59 \\
& $3 c-2 c$ & $3 b-2 b$ & $3 a-2 a$ & $3-2$ \\
\hline HF & 4.58 & 3.92 & 0.73 & 0.62 \\
MP2 & 3.94 & 0.39 & 2.23 & -0.98 \\
ZPE & -0.08 & -0.26 & 0.16 & -0.07 \\
$H_{0}$ & 3.86 & 0.13 & 2.39 & -1.05 \\
\hline \hline
\end{tabular}

${ }^{a}$ Relative electronic energies obtained with the $6-311++\mathrm{G}(2 \mathrm{~d}, 2 \mathrm{p})$ basis set; zero-point energies (ZPE) obtained at the B3LYP/6-311++G(d,p) level.

illustrated in Table III, a three-center H-bond interaction produces an enhanced shift to lower fields of the ${ }^{1} \mathrm{H}$ NMR signal. The effect is more pronounced in structures 1 and 3 .

In summary, the combination of $\nu_{\mathrm{N}-\mathrm{H}}$ and $b_{\mathrm{N}-\mathrm{H}}$ frequency shifts, intensification factors, ${ }^{1} \mathrm{H}-\mathrm{NMR}$ chemical shifts, and $\mathrm{N}-\mathrm{H}$ bond lengths lead us to the conclusion that positive cooperative effects are clearly present upon formation of a three-center $\mathrm{H}$ bond in structures 1 and 3 . However, the same indicators show that formation of a three-center $\mathrm{H}$-bond interaction in 2 and 4 is not accompanied by the manifestation of positive cooperative effects. In fact, the $\nu_{\mathrm{N}-\mathrm{H}}$ stretching modes and the intensity factors of 2 and 4 suggest a weakening of the $\mathrm{H}$-bond interaction, relative to $2 a$ and $4 a$, respectively.

Energetics. The relative stability of a two-center $\mathrm{H}$ bond in a six-membered ring over that in a five-membered ring is displayed in Table IV. It is seen that the relative energies depend on the level of theory. At the HF level, $4 a$ is clearly more stable than $4 b$. At the MP2 level, the stability of $4 a$ over $4 b$ is increased by $0.88 \mathrm{kcal} / \mathrm{mol}$. Also at the HF level, $3 a$ is much more stable than $3 b$, whereas $2 a$ is less stable than $2 b$. At the MP2 level, however, the stability of $3 a$ over $3 b$ is significantly reduced by $1.90 \mathrm{kcal} / \mathrm{mol}$, whereas $2 a$ is now much more stable than $2 b$. The results show the need to use correlated methods to better account for the $\mathrm{H}$ bond interaction, and for the enhanced electron delocalization that is taking place through the aromatic rings. For large systems, however, energy calculations with higher correlated methods and larger basis sets become rapidly impractical. It is seen that zero-point energy corrections to the energies are small for $4 a-4 b$, and $3 a-3 b$, and negligible for $2 a-2 b$, and $1 a-1 b$.

One notable feature of the energy results is the reduction of the stability of the six-membered ring conformations, upon replacement of either carbon-carbon double bond in $4 a$ and $4 b$ by a phenyl group. The effect is very significant in $3 b$ where the phenyl group is part of the five-membered ring. In fact, $3 a$ is just $0.78 \mathrm{kcal} / \mathrm{mol}$ more stable than $3 b$. The presence of two phenyl groups $(1 b, 1 a)$ actually reverses the stability order at both the HF and MP2 levels.

The reduced stability of a six-membered ring may be attributed in part to the geometric changes brought about by the presence of a phenyl ring. Table II shows, for instance, 
TABLE V. Mulliken charge distributions $(e){ }^{\mathrm{a}}$

\begin{tabular}{lcccc}
\hline \hline & $4 b$ & $3 b$ & $2 b$ & $1 b$ \\
\hline$q_{\mathrm{N}}$ & -0.28 & -0.39 & -0.25 & -0.38 \\
$q_{\mathrm{O}}{ }^{\mathrm{b}}$ & -0.39 & -0.55 & -0.39 & -0.55 \\
$q_{\mathrm{H}}$ & 0.23 & 0.24 & 0.23 & 0.24 \\
& $4 a$ & $3 a$ & $2 a$ & $1 a$ \\
\hline$q_{\mathrm{N}}$ & -0.28 & -0.39 & -0.28 & -0.43 \\
$q_{\mathrm{O}}$ & -0.46 & -0.46 & -0.57 & -0.56 \\
$q_{\mathrm{H}}$ & 0.25 & 0.27 & 0.26 & 0.29 \\
& 4 & 3 & 2 & 1 \\
\hline$q_{\mathrm{N}}$ & -0.34 & -0.51 & -0.35 & -0.56 \\
$q_{\mathrm{O}}{ }^{\mathrm{b}}$ & -0.39 & -0.57 & -0.39 & -0.57 \\
$q_{\mathrm{O}}{ }^{\mathrm{c}}$ & -0.46 & -0.45 & -0.58 & -0.58 \\
$q_{\mathrm{H}}$ & 0.29 & 0.36 & 0.32 & 0.41 \\
\hline \hline
\end{tabular}

${ }^{a}$ Mulliken charges computed at the B3LYP/6-311++G(2d,p).

${ }^{\mathrm{b}}$ Oxygen atom involved in the five-membered $\mathrm{H}$-bond structures.

${ }^{\mathrm{c}}$ Oxygen atom involved in the six-membered H-bond structures.

that the H-bond geometry of structure $3 b$ exhibits a significant improvement over that of structure $4 b$. The corresponding geometric changes observed in $3 a$ relative to $4 a$ are not as significant. It is also seen that the presence of a phenyl ring in structure $2 a$ improves, relative to $4 a$, the H-bond geometry, whereas only minor changes are seen in going from $4 b$ to $2 b$. Despite these geometric changes, we still see a reduction in stability of the six-membered ring in $2 a-2 b$ compared to $4 a-4 b$. Thus factors other than changes in the $\mathrm{H}$-bond geometries need to be considered to better understand the relative stabilities of the structures.

Trends in the electronic charge redistributions may provide some additional insight into the relative stabilities of the five- and six-membered H-bond structures. Table V displays the computed Mulliken charges of the atoms directly involved in the H-bond interactions, i.e., $\mathrm{H}, \mathrm{N}$, and $\mathrm{O}$. It is seen that the major change in going from $4 a$ to $3 a$ is an increase of the negative charge on the nitrogen atom. More substantial changes are observed, though, in going from $4 b$ to $3 b$, where the negative charge of the oxygen atom is increased along with that of the nitrogen atom. Thus the secondary electrostatic interaction ${ }^{10,11}$ between nitrogen and oxygen is expected to be more repulsive in $3 b$. In fact, $3 a$ is 3.01 $\mathrm{kcal} / \mathrm{mol}$ more stable than $3 b$ at the HF level. Accordingly, the energetic enhancement of the H-bond interaction in $3 b$, expected from geometry considerations, can really be appreciated once the important dispersion energy component is included at the MP2 level.

A similar Mulliken charge analysis helps rationalize the relative stability of $2 a$ and $2 b$. From Table V, it is seen that an increase in the negative charge of the methoxy oxygen occurs in going from $4 a$ to $2 a$, while no important changes are seen in going from $4 b$ to $2 b$. Thus a more repulsive nitrogen-oxygen interaction is expected in $2 a$ than in $2 b$. In fact, $2 a$ is actually $0.19 \mathrm{kcal} / \mathrm{mol}$ less stable than $2 b$ at the HF level. Therefore, the energetic enhancement of the $\mathrm{H}$-bond interaction in $2 a$, expected from geometry considerations, is partly offset by the secondary repulsive nitrogenoxygen electrostatic interaction. The MP2 method is again particularly important to better describe the energetics of the $\mathrm{H}$-bond interaction. The relative stability of $1 a$ and $1 b$ may also be traced partly to the combination of geometric and electrostatic effects.

It is interesting to note that the hydrogen atom becomes progressively more positive as the H-bond structures go from a five- to a six-membered ring, and then to a three-center $\mathrm{H}$-bond interaction. This is more evident in the sequences $3 b \rightarrow 3 a \rightarrow 3$, and $1 b \rightarrow 1 a \rightarrow 1$, respectively, which are also the ones where positive cooperative effects are clearly present.

Additional insight into the energetics can be gained from models $2,2 a-2 c$, and their structural isomers $3,3 a-3 c$. These models differ from each other in the relative position of the phenyl and vinyl groups. The structural isomers can be used to shed light into the influence of the position of the phenyl ring on the relative stability of the isomers. Table IV shows that the reference structure is more stable if the phenyl group is attached to the amide carbon $(2 c)$ rather than to the nitrogen atom $(3 c)$. However, this stability is decreased upon formation of a two-center $\mathrm{H}$ bond. The effect is more drastic for the $3 b-2 b$ pair. The picture that emerges is that the five-membered ring conformation is energetically stabilized by having a phenyl group attached to the nitrogen atom $(3 b)$, so much that $3 b$ is just $0.13 \mathrm{kcal} / \mathrm{mol}$ less stable than $2 b$, after correlation and zero-point energy corrections. Interestingly, having a phenyl group attached to the amide carbon seems to have an adverse energetic effect on the sixmembered ring conformation. If it were to provide additional stabilization, we would expect a larger relative stability of $3 a$ over $2 a(2.39 \mathrm{kcal} / \mathrm{mol})$, compared to that of $3 c$ over $2 c$ $(3.86 \mathrm{kcal} / \mathrm{mol})$. It is seen that the formation of a three-center $\mathrm{H}$ bond actually reverses the stability of $3 c$ over $2 c$. Table IV shows that structure 3 is $1.05 \mathrm{kcal} / \mathrm{mol}$ more stable than structure 2. This reverse in stability can be traced to the combined energetic effects of having a phenyl group attached to nitrogen in the five-membered ring (energetically favorable), and having a phenyl group attached to the amide carbon in the six-membered ring (energetically unfavorable).

Isodesmic reactions. We devised some relevant isodesmic reactions as an alternate tool for calculating the enthalpy change associated with the formation of an intramolecular three-center interaction. Because of the conservation of the total number and types of bonds, good results can be obtained for isodesmic reactions involving very similar systems due to the cancellation of errors on the two sides of the reaction., ${ }^{2,12}$ The B3LYP/6-311+ $+\mathrm{G}(\mathrm{d}, \mathrm{p})$ optimized geometries were used to calculate MP2/6-311+ $+\mathrm{G}(2 \mathrm{~d}, 2 \mathrm{p})$ energies. After zero-point energy corrections, the enthalpy values (at $0 \mathrm{~K}$ ) are obtained for the following reactions:

\begin{tabular}{cc} 
Reaction & $\Delta H_{0}(\mathrm{kcal} / \mathrm{mol})$ \\
\hline (A) $4 a+4 b \leftrightarrow 4+4 c$ & 0.47 \\
(B) $3 a+3 b \leftrightarrow 3+3 c$ & 0.52 \\
(C) $2 a+2 b \leftrightarrow 2+2 c$ & 0.23 \\
(D) $1 a+1 b \leftrightarrow 1+1 c$ & 0.51
\end{tabular}

The isodesmic gas-phase reactions show that the formation of the three-center $\mathrm{H}$-bond structures $1-4$ from their 
corresponding five- and six-membered ring conformations is marginally an endothermic process. This is not to be regarded necessarily as the manifestation of negative cooperativity, but rather as evidence that factors other than hydrogen bonding can be important in determining the energetics of conformations containing intramolecular $\mathrm{H}$ bonds. ${ }^{13}$

\section{SUMMARY}

A comprehensive $a b$ initio study has been conducted on a series of amide structures containing intramolecular twoand three-center H-bonding interactions. The superior strength of a two-center $\mathrm{H}$ bond in a six-membered ring as opposed to a five-membered ring is demonstrated by a consortia of H-bonding indicators: $\mathrm{N}-\mathrm{H}$ frequency shifts, intensification factors, $\mathrm{N}-\mathrm{H}$ bond lengths, and ${ }^{1} \mathrm{H}$ NMR chemical shifts. The same indicators are used to reveal the existence of nonpairwise additive phenomena upon formation of the three-center intramolecular H-bond systems 1 and 3. Several factors may be responsible for the observed positive cooperativity: (1) the semirigid structure of the three-center H-bond systems, (2) the enhanced electron $\pi$ delocalization facilitated by the aromatic rings, (3) the weak $\mathrm{C}-\mathrm{H} \cdots \mathrm{O}$ hydrogen bonding ${ }^{13}$ between the amide carbonyl $\mathrm{O}$ and its nearest aromatic $\mathrm{H}$ atoms. Such a positive cooperativity helps rationalize the frequent occurrence of three-center $\mathrm{H}$ bonds in the crystal structures of small molecules ${ }^{14}$ and biomacromolecules. ${ }^{15}$ Unlike the three-center $\mathrm{H}$ bonding which was found to be weaker than two-center $\mathrm{H}$ bonding in flexible peptide systems, ${ }^{16}$ the three-center systems 1 and 3 are rather robust, which, when combined with proper structural scaffolds, should serve as a reliable basic folding unit for designing a variety of unnatural, folded structures. ${ }^{17}$

The $a b$ initio results show that the relative stability of isomers containing a $\mathrm{H}$ bond does not necessarily parallel the strength of the H-bond itself. In fact, the results are sometimes counterintuitive. The use of geometric and spectroscopic parameters proves useful in examining cooperative phenomena particularly in intramolecular multicenter $\mathrm{H}$ bond systems.

\section{ACKNOWLEDGMENTS}

This work was supported by grants from NASA (NAG58785), NIH (GM59235), ACS-PRF (34456-AC4), and NSF (ECS9900127). Part of this work was completed utilizing the Research Computing Facility of the University of NebraskaLincoln.

${ }^{1}$ R. D. Parra, M. Furukawa, B. Gong, and X. C. Zeng, J. Chem. Phys. 115, 6030 (2001), preceding paper.

${ }^{2}$ A. Simperler and W. Mikenda, Hydrogen Bond Research (SpringerVerlag, Wien, 1999), p. 66.

${ }^{3}$ P. L. Huyskens, J. Am. Chem. Soc. 99, 2578 (1977); H. Kleeberg, D. Klein, and W. A. P. Luck, J. Phys. Chem. 91, 3200 (1987).

${ }^{4}$ S. Scheiner, Hydrogen Bonding: A Theoretical Perspective (Oxford University Press, New York, 1997), Chap. 5 and references therein.

${ }^{5}$ M. J. Frisch, G. W. Trucks, H. B. Schlegel et al., GAussian 98, Revision A.9, Gaussian, Inc., Pittsburgh, PA, 1998.

${ }^{6}$ I. R. Gould and I. H. Hillier, J. Mol. Struct.: THEOCHEM 314, 1 (1994); I. J. Kurnig, M. M. Szczesniak, and S. Scheiner, J. Chem. Phys. 87, 2214 (1987).

${ }^{7}$ G. C. Pimentel and A. L. Mcclellan, The Hydrogen Bond (Freeman, New York, 1960).

${ }^{8}$ R. D. Parra and X. C. Zeng, J. Chem. Phys. 110, 6329 (1999); O. Mó, M. Yáñez, ibid. 107, 3592 (1997).

${ }^{9}$ R. Konrat, M. Tollinger, G. Kontaxis, and B. Kräutler, in Hydrogen Bond Research (Springer-Verlag, Wien, 1999), p. 17.

${ }^{10}$ J. Yang and S. H. Gellman, J. Am. Chem. Soc. 120, 9090 (1998); S. H. Gellman, G. P. Dado, G. B. Liang, and B. R. Adams, ibid. 113, 1164 (1991); R. R. Gardner and S. H. Gellman, ibid. 117, 10411 (1995).

${ }^{11}$ W. L. Jorgensen and J. Pranata, J. Am. Chem. Soc. 112, 2008 (1990); J. Pranata, S. G. Wierschke, and W. L. Jorgensen, ibid. 113, 2810 (1991).

${ }^{12}$ K. B. Wiberg, C. M. Hadad, P. A. Rablen, and J. Cioslowski, J. Am. Chem. Soc. 114, 8644 (1992).

${ }^{13}$ G. R. Desiraju, Acc. Chem. Res. 29, 441 (1996).

${ }^{14}$ G. A. Jeffrey, An Introduction to Hydrogen Bonding (Oxford University Press, New York, 1997); R. Parthasarathy, Acta Crystallogr., Sect. B: Struct. Crystallogr. Cryst. Chem. B25, 509 (1969); P. G. Jönsson and A. Kvick, ibid. B28, 1827 (1972); G. A. Jeffrey and S. Takagi, Acc. Chem. Res. 11, 264 (1978); C. H. Görbitz and M. C. Etter, J. Chem. Soc., Perkin Trans. 2 1992, 131; C. Huang, L. A. Cabell, and E. A. Anslyn, J. Am. Chem. Soc. 116, 2778 (1994).

${ }^{15}$ H. C. M. Nelson, J. T. Finch, B. F. Luisi, and A. Klug, Nature (London) 330, 221 (1987); J. E. Koehler, W. Saenger, and W. F. van Gunsteren, J. Biomol. Struct. Dyn. 6, 181 (1988); R. Preissner, U. Egner, and W. Saenger, FEBS Lett. 288, 192 (1991); D. S. Goodsell, M. L. Kopka, and R. E. Dickerson, Biochemistry 34, 4983 (1995); G. A. Jeffrey and W. Sanger, Hydrogen Bonding in Biological Structures (Springer-Verlag, Berlin, Heidelberg, 1991).

${ }^{16}$ J. H. Yang and S. H. Gellman, J. Am. Chem. Soc. 120, 9090 (1998); J. H. Yang, L. A. Christianson, and S. H. Gellman, Org. Lett. 1, 11 (1999).

${ }^{17}$ J. Zhu, R. D. Parra, H. Zeng, E. Skrzypczak-Jankun, X. C. Zeng, and B. Gong, J. Am. Chem. Soc. 122, 4219 (2000). 